\title{
O profesorado de apoio á atención á diversidade, profesional clave na función orientadora
}

\section{Special needs support teacher, a key professional to perform school counseling work}

\author{
M. Montserrat Castro-Rodríguez* Ana Isabel Castro-Rodríguez** \\ *Departamento de Pedagogía y Didáctica, Universidade da Coruña, España **Departamento de Orientación, IES Melide, España
}

\begin{abstract}
Resumo
A relevancia social do Departamento de Orientación (DO) e a súa visibilización focalízase, con frecuencia, na figura do orientador ou orientadora, mientras que outros profesionais que forman parte de este quedan nun lugar subsidiario. O profesorado de apoio e o orientador precisan de un traballo conxunto imprescindible, porque os primeiros son os interlocutores directos e máis habituais co alumnado, co resto do equipo docente e incluso coas familias. Son estes profesionais os que aglutinan boa parte da información e do coñecemento alumnado con necesidades específicas de apoio educativo, independentemente de que traballen ou non co alumnado, pois a súa fución de apoio non se restrinxe ao alumnado senón tamén ao profesorado de aula no seu traballo diario. Nesta comunicación, preséntase unha reflexión entre dúas profesionais con esperiencia dende fai 12 e 6 anos respectivamente.

Palabras clave: Apoio, traballo cooperativo, orientación,
\end{abstract}

\begin{abstract}
The social relevance of school counseling departments are often focused on school counselor's actions, meanwhile the remaining professionals that contribute to school counseling work have held a subsidiary position. Support teachers and school counselors need to work collaboratively, because the former continues to be the main interlocutor with students, the rest of the teaching staff and even the students' families. They are the professionals that have the most information and knowledge about special needs students. They work directly with the student amd they help classroom teachers. This paper offers a reflection between two support teachers that have important work experience from 6 and 12 years respectively

Keywords: counseling, support, cooperative working
\end{abstract}

Se nos situamos no marco lexislativo español, encontramos que dende o RD 334/1985 que regula a Educación Especial e aposta pola integración do alumnado "disminuído ou inadaptado" e posteriormente, con a LOXSE, en principio, evoluciónase cara unha terminoloxía "máis inclusiva" e respectuosa coa diversidade. Fálase de que un dos principios fundamentais da escola obrigatoria será a atención á diversidade de alumnado (LOXSE, 1991; LOE, 2006). Preténdes unha escola para todos, onde todo o alumnado recibirá unha educación adecuada ás súas necesidades e características (LOE, 2006) contará cos recursos suficientes para conseguir o seu máximo desenvolvemento personal. Debido a isto, entran en escena unha serie de profesionais, especialmente profesorado, que teñen funcións específicas no so na atención directa aquel alumnado que presente Necesidades Específicas de Apoio Educativo (NEAE) de forma permanente ou temporal, senón tamén han de exercer unha función de apoio á aula e ao centro escolar na súa totalidade, co obxectivo fundamental de planificar e desenrolar propostas educativas inclusivas en xeral.

Neste marco conceptual, pódese dicir que se concibe a aparición dos Departamentos de Orientación (DO), coa pretensión de que "Deste xeito pódese asegurar que todos os compoñentes da comunidade escolar teñan acceso aos recursos de orientación educativa e, polo tanto, poidan realizar unha escolarización sen exclusións, que garanta a igualdade efectiva de oportunidades e preste os apoios necesarios, tanto ao alumnado que o requira como aos centros en que estea escolarizado (Consellería de Educación e Ordenación Universitaria, 2008: 8).

O DO ten a súa orixe, á súa constitución, as súas fucións e funcionamento, nos principos explicitados anteriormente. Dende a nosa perspectiva, cabe cuestionarse se realmente, despois de case dúas décadas de existencia, se coñece con profundidade e se, en xeral, se produce un verdadeiro aproveitamento das posibilidades que nos ofrece. Despois de unha longa traxectoria profesional como membros de este departamento, pois entre ambas persoas que asinamos esta comunicación, formamos parte de máis de 20 departamentos de centros que integran diferentes etapas educativas (CEIP, CPI, IES), afirmamos que quizás sexa un gran descoñecido, mesmo nas propias comunidades educativas.

En moitas ocasións, o único referente do DO é a súa xefatura, ignorando as importantes achegas que fan os outros membros participantes, e que moitas veces resultan cruais para a atención á diversidade en unha comunidade educativa.

$\mathrm{Na}$ presente comunicación, preténdese facer unha reflexión a interdependencia e complementariedade das 
funcións e os roles que poden exercer dentro do departamento os distintos profesionais que o constitúen. A especialidade e os distintos ámbitos de actuación e a interdisciplinariedade de todos os membros que o compoñen, facilitan unha visión máis global dunha realidade complexa, na que hai que intervir para evitar, solucionar, minguar problemáticas que afectan ao desenvolvemento individual e colectivo do alumnado, profesorado e familias que en el participan. En especial, farase referencia ao rol do profesorado de apoio ás necesidades específicas de apoio educativo, destacando tendencias que observando a situación de moitos centros escolares.

\section{O Departamento de Orientación e os seus compañentes}

Retomando a idea exposta na introdución de esta comunicación, sabemos, que, con frecuencia, falar do DO asóciase directamente coa súa xefatura, exercida por un profesional da orientación, que posúe unha formación específica e especializada que o capacita para o exercicio de unhas determinadas funcións. Posiblemente, esa simplificación que se produce cando se identifica un órgano colectivo con un so membro do equipo, pode conlevar a unha interpretación sesgada e mesmo desprestixiada das súas verdadeiras funcións.

En canto aos do departamento, varía de Educación Infantil (EI) e Primaria (EP) e a secundaria. Segundo a Decreto 120/1998, en unha escola de EI e EP, ata o de agora formaban parte as persoas quñe exercían a coordinación de todos os ciclos da EP e a coordinadora de EI, se a houbera, tamén o profesorado de apoio educativo (Pedagoxía Terapéutica (PT), Audición e Linguaxe (AL)), e de ser o caso, coordinadores de outros centros que puideran estar adscritos a ese departamento, ademais do propio orientador/orientadora. En secundaria, ademais do profesorado de apoio, PT e AL e os orientadores, están presentes titores e titoras de cada un dos ámbitos lingüístico-social e científico-tecnolóxico, procurando sempre que estean representadas todas as etapas que se impartan no centro.

Posiblemente, na configuración do sistema de orientación en Galicia, o optar pola creación e DO está relaciónado coa visión de interdisciplineriedade, representación de distintos colectivos, o que vencella directamente coa dimensión do traballo colectivo, colaborativo ou cooperativo. As respostas á diversidade, parece por coherencia, teñen que vir da pluralidade de visións que se complementan. Por este motivo, os profesionais que se necesitan nos centros educativos teñen que traballar dende a perspectiva de complementariedade das súas intervencións co obxectivo de alcanzar propostas globalizadas e inter ou multidisciplinares, que aborden as diferentes necesidades e que fagan uso dos recursos adecuados para que todo o alumnado teña a posibilidade de acceder ao coñecemento, incorporalo ao seu input e logo aplicalo na vida ordinaria.

As funcións e achegas de cada cada colectivo representado no departamento son diferentes e son imprescindibles nun proceso de atención á diversidade, que segundo, ten que ser asumida dende o centro educativo en xeral, que contará co seu plan de atención á diversidade (PAD) de acordo con decreto 229/2011 de atención á diversidade. Un PAD que recollerá a valoración das necesidades e potencialidades que se conviven no centro educativo e as medidas e iniciativas que permitan responder á diversidade de persoas que se forman nel. A continuación faremos una reflexión sobre as principais achegas de cada colectivo ao traballo que desempeña o da función orientadora.

O profesorado representante de etapa, ciclo, área

A participación do profesorado que representa as etapas, os ata agora ciclos de EP ou as distintas áreas de coñecemento achega ao departamento o coñecemento real do que está pasando nas aulas, no día a día co seu alumnado, co profesorado. Son os que en primeira persoa coñecen a evolución xeral da vida do centro, tanto pola súa función de representación de un colectivo que lle conta as súas situacións individuais e colectivas como polo exercicio de convivencia directa co alumnado, como docentes que imparten coñecementos procedentes de distintas disciplinas. Ademais falan coas familias. Saben e coñecen ao seu alumnado. A isto hai que lle engadir que son profesionais que teñen formación específica nos distintos ámbitos científicos, o que resulta imprescindible á hora de seleccionar, secuenciar os contidos, os obxectivos, a formulación de tarefas de acordo coas necesidades do alumnado. A isto hai que as súas funcións de representación do ciclo ou da área de coñecemento implica a participación en outros órganos de decisión e xestión do centro, o que lles proporciona unha visión máis completa tanto do que está a ocorrer, como das decisións que se adoptan que poidan estar coordinadas e interrelacionadas.

\section{$O$ profesorado procedente de centros adscritos}

A dispersión do noso país, xunto coa baixo índice de natalidade, en especial no rural, e as decisións políticas de dotación de DO determinan que, con maior frecuencia en centros de EEI, CEP ou CEIP haxa xefaturas de DO que teñen que realizar o seu traballo en dous ou máis centros da contorna. No caso de centros que so teñen ensino secundario deberán estar coordinados con centros de primaria, independentemente de que dispoñan estes teñan ou non departamento, debido a que o alumnado cando remate a etapa de EP, o centro de referencia ao que deberán asistir será ese de ensino secundario. Por este motivo, resulta imprescindible unha coordinación vertical, co obxectivo de manter unha coherencia con respecto á atención á diversidade (Valín, D. y Castro, M., 2007). Neste senso, as achegas do profesorado dos centros adscritos son nucleares para o exercicio dunha orientación inclusiva, por ende, contextualizada, pois a non presenza do orientador ou orientadora na escola de forma permanente dificulta e fragmenta a información coa que conta este profesional.

\section{$O$ profesorado de apoio}

O profesorado de apoio máis común nos centros educativos son o PT e o AL. O primeiro, o de máis antigüidade se nos referimos á súa incorporación á escola. O AL incorpórase aos centros escolares a inicios da década dos noventa, a partir da LOXSE. 
Quizás esta orixe condicionen en boa medida o input que a sociedade ten sobre cada un de eles.

O PT, como o seu nome suxire, ten a súa orixe no movemento da pedagoxía médica que aparece en Europa e EE:UU a fins do século XIX, aínda que o seu verdadeiro desenvolvemento se produce no XX porque o seu traballo adquire maior profesionalización e expansión. Unha denominación que nos retrotrae a unha historia moi lonxana, que, a priori, pode distar moito das funcións que exerce na actualidade, aínda que se cadra, moitas prácticas realizadas en algúns centros non son tan distantes de esa trasnoitada historia. Centrándonos na evolución da concepción a atención á diversiade, teríamos que remontarnos ao Real Decreto 334/1985 onde se inicia un proceso de cambios significativos no que a atención á diversidade se refire e, por tanto, nas funcións que se lle atribúen aos profesionais do apoio. Coa LOXSE prodúcense dous fitos importantes: a aparición do profesorado de AL e o cambio da concepción sobre a atención á diversidade dentro da aula, tanto de quen son os seus destinatarios, coma, por outra parte, a atención á diversidade non recae exclusivamente nos profesionais de apoio, senón en todo o profesorado do centro. Con esta lei iníciase un proceso que seguirá coas leis posteriores, a LOE e a LOMCE, aínda que cada unha delas cos seus matices. Coa LOE preténdese introducir a concepción de que a diversidade non se refire só a persoas que presentan algunha diversidade funcional específica. Evidentemente, isto introduce cambios importantes no traballo dos profesionais de apoio. Uns profesionais que xa non responderán a un principio de especialista en todo, senón que se diversifica, entendendo que as necesidades formativas do profesorado pode ser diferentes.

Ao longo de estes anos, tal como afirma Moya (2012) producíronse cambios importantes nos roles que desempeñan estes profesionais, aínda que as prácticas levadas en moitos centros, se cadra, aínda rezuman un pasado pouco desexable dende o punto de vista da inclusión educativa.

A acción docente del profesor/a de PT e AL está ligado a los principios de la atención a todo o alumnado, pero é certo que existe unha tradición na súa conexión co alumnado con necesidades específicas de apoio educativo, especialmente no caso daqueles centros que aposten por unha filosofía máis integradora ou mesmo segregadora. Entre as funcións máis coñecidas e quizás máis tradicionais están as relacionadas co traballo directo coas persoas que presentan NEAE, dentro ou fóra da aula, pero tamén coa función asesora que poden desempeñar en relación tanto co profesorado coma coas familias, tanto no deseño e desenvolvemento de estratexias e de recursos que forezan a relación con ditos estudantes, melloren a súa calidade de vida escolar e persoal, como non debemos esquecer a permeabilidade e a trasferencia de coñecementos escolares á vida ordinaria.

Tendo en conta a estreita relación de estes profesionais coa atención á diversidade xeral que se realizsa no centro, a continuación imos analizar polo miúdo as súas principais funcións en relación directa cos da xefatura do departamento.

\section{Contribucións do profesorado de apoio á función orientadora}

O punto de partida é que os mestres e mestras de apoio poderan exercer as súas funcións dentro ou fóra das aulas ordinarias onde hai alumnado con Necesidades Específicas e Apoio Educativo (NEAE), en colaboración con cualquera membro do equipo docente na aula poderá estar realizar actividades apoio á docencia, é dicir, traballando directamente cos discentes, tanto co que presenta NEAE como el resto de estudantes, en función do modelo de apoio polo que opte (Moya, 2002). Tamén asesorando ao profesorado ordinario para realizar a súa actividade docente, procurando adaptar as prácticas de ensino-aprendizaxe ás necesidades específicas da diversidad individual e colectiva da escola. Trátase de colaborar co profesorado que realiza o seu labor nas aulas ordinarias, ou na procura de estratexias, metodoloxías e incluso materiais para facilitar que todo os nenos e nena presentes na aula participen e sexan visible e participen de un proxecto educativo común.

Unha das funcións específicas da orientación é a valoración das necesidades e potencialidades, tanto do alumnado coma do profesorado e do centro en xeral, co fin de adaptar as medidas á realidade na que se van desenvolver. Neste sentido, a presenza do profesorado de apoio directamente nas aulas, permítenlle ter acceso a información que o orientador ou orientadora non podería posuír, tendo en conta que maioritariamente non se vai estar presente no desenvolvemento da práctica educativa que ten lugar nas clases. As interaccións que se producen nas aulas son complexas e, a veces, con matices dificilmente descritibles e mesmo ignoradas, por desconsideralas por falta de coñecemento, por non ter a dimensión da súa posible repercusión ou polo simple feito de que os protagonistas non son conscientes de que se producen. A presenza asidua e non anecdótica de dúas profesionais na aula pode ser un contributo importante nos procesos de análise, interpretación e valoración do que acontece.

O profesorado de PT e AL encargarase de colaborar co resto de docentes no desenvolvemento e execución da acción educativa proposta desde o DO, dentro ou fóra da aula ordinaria. Poderíamos considerar esta situación como de ponte entre a acción orientadora e o traballo realizado nas clases ordinarias ás que asiste un alumnado con NEAE. A presenza do orientador non pode ser "continua", debido en boa media pola cantidade de funcións que desempeña, pero tamén pola natureza da atención á diversidade que debe levar a cabo o equipo docente correspondente con cada estudante, con todos os estudantes en cadansúa aula. A colaboración no proceso de planificación, selección da metodoloxía, estratexias, recursos máis axeitados para cada contido, cada obxectivo, cada momento, na práctica diaria establécese entre o profesorado de apoio e o resto de mestres. Especialmente, no caso dos centros nos que a orientadora non permanece a tempo completo. 
A pesar de que a lexislación actual, a priori, establece que os apoios ao alumnado se deben facer maioritariamente na aula ordinaria, é necesario recoñecer que a realidade dos centros escolares galegos, en unha proporción significativa, os apoios teñen lugar fóra de dita aula (Núñez, T., 2008). Somos conscientes de que moito profesorado de apoio, ben sexa por convicción, ben por dificultades ante 0 número de estudantes cos que teñen que traballar, leva ao alumnado as aulas de apoio. Lembremos a asistencia á aula de apoio está regulada, cando o modelo de escolarización acordado seguindo as pautas legais ad hoc así o aconsellan, e que debe quedar restrinxido a aquelas persoas que debido á diversidade funcional que os caracteriza, consideráse que é a modalidade máis axeitada. Sen entrar nos pormenores de esa decisión de "sacar" o alumnado da clase, neste modelo de traballo, a colaboración entre equipo docente e o profesorado de apoio non sempre é unha realidade. Moitas veces o PT e/ou AL desenvolve o seu traballo de forma unilateral. Nestes casos, as achegas de estes profesionais ao DO poden ser moi enriquecedoras. Por unha parte, pode existir coordinación en tanto que se establecen unha serie de reparto ou compartimento de responsabilidades e funcións específicas. Por outra, pódese dar o caso de que non haxa coordinación directa entre profesorado, e o único nexo en común sexa os informes e as decisións que se adoptan dende o DO.

Otra das funcións do profesorado de apoio é de colaborar no proceso de elaboración das Adaptaciones Curriculares (AC), aínda que a elaboración das AC recae sobre o profesorado que imparte docencia ao alumnado con NEAE nas áreas a adaptar, ben sexa tutora ou especialista. Cómpre non esquecer que a realización de esta medida de atención á diversidade, especialmente no que atingue ás adaptacións significativas, lévanse a cabo cando xa se teñen esgotado todas as medidas ordinarias convenientes. Por tanto, na mioría dos casos, existe unha ampla traxectoria compartida, aínda que non sempre se poida falar de colaboración, pero cando menos de que se comparte información durante un período onde as decisións de adecuación, tanto de recursos como de estratexias esixiron tomas de decisións conxuntas. Neste sentido, a formación profesional do profesorado de apoio debeu resultar clave ao longo do proceso, pois achegan información, estratexias e recursos que permiten graduar e secuenciar as distintas medidas de atención á diversidade. Dende a nosa experiencia, a xefatura de DO precisa de un traballo moi próximo e colaborativo con todo o profesorado co obxectivo de adecuar o máximo posible as medidas a adoptar.

A participación dos profesionais do apoio educativo nas distintas como a CCP ou calquera das outras ordinarias que contribúen ao funcionamento do centro, como dicíamos en parágrafos anteriores, soe ser unha oportundiade interesante para que o DO poida introducir estratexias ou colaborar na toma de decisións para poder adoptar medidas xerais que favorezan a diversidade en todo o centro e mesmo na comunidade educativa.
Existe unha longa tradición nas nosas aulas en asociar ao profesorado de apoio educativo como "o respondable" do alumnado con NEAE. Un estigma histórico que é un indicio máis da segregación que se practicou con estes estudantes. Iso acostuma tamén a xenerar unha forte relación entre as familias e o PT e/ou AL. Por este motivo, a frecuencia da sinteraccións e posiblemente outras variables contribúen a que estes profesionais recaban moita que as propias familias lle suministra.

De todos é coñecido, que os mestres e mestras de apoio, aglutinan moita información sobre intereses e motivacións do alumnado con NEAE, das interaccións de estes co resto de compañeiros e compañeiras, os seus medos e os seus soños, as súas necesdiades, etc

\section{Obstáculos ao traballo compartido entre} profesionais de apoio e orientación

Con frecuencia, o traballo do PT, AL e Orientador non é do todo comprendido. Quizás por non ser o suficientemente coñecido, pero tamén existe unha longa tradición na que o seu labor se entendía dende a perspectiva dunha intervención "curativa" e incluso asistencial, modalidades de apoio aínda perduran nas aulas galegas.

Por outra banda, non esquezamos, que o colectivo de alumnado con NEAE aínda segue padecendo a exclusión por unha parte considerable da sociedade e incluso certo sector del profesorado. As proxeccións de expectativas acostuman a ser negativas. Todo isto a veces afecta moi directamente ao profesorado especialista e aos orientadores, quen, con relativa frecuencia, se atopan en situacións de incomprensión das súas propias intervencións. Moitas veces os resultados do traballo realizado con certo alumnado con NEAE e a atención á diversidade teñen repercusión a longo prazo, co que o resto do profesorado e/ou a familia e/ou a comunidade educativa non sempre poden percibir de inmediato os resultados de un traballo realizado polos especialistas.

Son moitos os autores e as investigacións que falan do endeble entramado que se foi urdindo no sistema educativo español para a atención á diversidade (Núñez, Ma , T. 2008; Parrilla, A., 2009), dado que tres décadas despois se aproba unha lei que, a priori, volve introducir sospeitosas medidas que poden contribuir á segregación de moitos nenos e nenas.

Un dos principais obstáculos que se están vivindo na actualidade con respecto son os recortes en recursos humanos que están afectando de forma moi especial ao profesorado de apoio. En Galicia son numerosos os centros nos que se suprimiron prazas, producíndose un aumento considerable de profesionais de apoio e de orientación que comparten un ou máis escolas ao longo da semana. O que orixina grandes dificultades que afectan por exemplo á realización de xuntanzas do DO. A ratio de alumnado con NEAE por profesional de apoio é moi elevada.

\section{Conclusións}

O funcionamento do DO depende en boa medida dos traballo realizado por todos os seus integrantes, debido ao carácter complementario que poden proporcionar. 
No caso específico do profesorado de apoio, as súas achegas resultan fundamentais porque, debido á súa formación e os ámbitos específicos de actuación, recolle experiencias e información que será moi valiosa, non so para valoración do traballo desenvolto, senón tamén para a axudar a elaborar e a entender todo o entramado que supón a tención á diversidade. Tendo en conta esta premisa, o traballo cooperativo entre profesionais debe ser un aspecto clave a valorar e cuidar en todo o sistema educativo.

Nestes últimos anos, as medidas adoptadas dende a administración están a ser un obstáculo importante para a realización do seu traballo. Aos xa tradicionais obstáculos cos que se atopou a atención á diversidade, nos últimos anos a redución de prazas de profesorado de apoio, aumentos de ratio, as itinerancias entre centros de docentes e orientadores, poden dificultar o avance no proceso de escola que debe camiñar cara a inclusión.

\section{Referencias}

Cardona, $\mathrm{M}^{\mathrm{a}}$ (2005). Diversidad y educación inclusiva. Madrid: Pearson/Prentice Hall

Consellería de Educación e Ordenación Universitaria (2008). Rede de Orientación de Galicia. Santiago de Compostela: Xunta de Galicia

Decreto 120/1998 do 23 de abril, polo que se regula a orientación educativa e profesional na Comunidade Autónoma de Galicia

Decreto 120/1998, do 23 de abril, polo que se regula a orientación educativa e profesional na Comunidade Autónoma de Galicia
Decreto 229/2011, do 7 de decembro, polo que se regula a atención á diversidade do alumnado dos centros docentes da Comunidade Autónoma de Galicia nos que se imparten as ensinanzas establecidas na Ley Orgánica 2/2006, do 3 de maio, de educación

Lei Orgánica 2/2006, de 3 de mayo, de Educación

Ley Orgánica 1/1990, de 3 de octubre de 1990, de Ordenación General del Sistema Educativo

Moya, A. (2002). El profesorado de apoyo ¿dónde?, ¿cuándo?, ¿cómo?... realiza su trabajo. Málaga: Aljibe

Moya, A. (2012). El profesorado de apoyo en los centros ordinarios. Nuevas funciones, nuevas contradicciones. Educatio siglo XXI: Revista de la Facultad de Educación, 30 (1), 71-88

Núñez, T. (2008). De la segregación a la Inclusión Educativa. Noia: Laiovento

Parrilla, A. (2009). "A educación inlcusiva: unha dirección a seguir localmente" en Revista Galega de Educación, pp. 9-13

Porter, G. L. (2005). "El reto de la diversidad y la integración en las escuelas" en La escuela inclusiva. Prácticas y reflexiones. Barcelona: Gráo, pp. 15-25

Real Decreto 334/1985 que regula la Educación Especia Snell, M. (2006). La escuela inclusiva. Sevilla: Fundación ECOEMV

Valín, D. y Castro, M. (2007). "La integración del Educador Social en la Escuela Comprehensiva: Una respuesta a las necesidades educativas integrales"en Aula de Innovación Educativa, pp. 18-23

Verdugo, M.A. (2009). "El cambio educativo desde una perspectiva de calidad de vida" en Revista de Educación, 349, pp. 23-4. 